\title{
PHYSIOTHERAPY CLINICAL EDUCATOR'S NEEDS
}

\begin{abstract}
Physiotherapy clinicians have been involved in student clinical education since the early days of physiotherapy training. As the physiotherapy practice and student learning has changed over the last three decades, so have the role of the clinical educators. Little has been done though, to prepare or support the clinical educa-

\section{MBAMBO NP, M Phys T}

Department of Physiotherapy, MEDUNSA tors in this new role which is more complex. The needs of the clinical educators in terms of their involvement in clinical education and their training for this role are established and recommendations are made to meet these needs.
\end{abstract}

\section{INTRODUCTION}

Clinical education forms a major part of the teaching programme for physiotherapy education and should provide a stimulating foundation for integrating and internalizing the theoretical knowledge learnt in lectures and during self study. Clinical activities and experiences that are planned as part of physiotherapy education should provide this stimulating foundation and the provision thereof depends on effective collaboration and communication between the universities and providers of clinical education.

The experiences that the students are supposed to gain during clinical education include treating of patients with various medical conditions, working with other health care team members, and decision making concerning other aspects of the patients' wellbeing, and problem solving around the patients' illness or disability. The clinicians who are charged with the task of clinical education of students, plan and conduct clinical activities and experiences that will fit in with the day to day running of a clinical department.

The clinical educators therefore play a pivotal role in the training of the students because:

\section{CORRESPONDENCE:}

NP Mbambo

Department of Physiotherapy

Medical University of Southern Africa

P.O. Box 1637

Medunsa

204

South Africa
- they are the ones who have close and frequent contact with the students during their practical time in the clinical settings

- the students treat the clinicians' patients, and

- they are the members of the health care team to whom the students must be introduced and into whose departments they need to be incorporated.

Coates (1991) defined the role of the clinical educators by suggesting that:

Clinicians are the members of our profession who are spending the majority of their time treating patients, achieving the mastery level of their clinical skills and becoming familiar with modern equipment. It is these members of our profession who have so much to offer students and should therefore be at the forefront of the clinical education process.

\section{CHANGES IN THE PHYSIOTHERAPY PROFESSION}

Over the last three decades the physiotherapy profession has evolved in clinical practice, student learning and clinicians' involvement in students learning. Physiotherapy practice has developed from the dependency of the 1960s where the clinicians worked under the direction of medical practitioners, to full autonomy (Cross, 1994). As these changes were taking place in clinical practice, the role of the clinicians involved in student training changed from a clinical instructor who was drilling learners to produce traditional procedures (Wastaff, 1988) to that of a clinical educator who is required to facilitate students to cope with change, to make judgements and take responsibility for those judgements, and to deal with the complexities of real-world clinical practice (Higgs, 1992). The need to improve professional status and the credibility of professional decisions saw a change from diploma-based programmes to degree-based programmes. This change in training also contributed to the change in the clinical supervisor's role, which was from a supervisor to an educator. What is the difference then between education and supervision? Daloz (1986) defined education as:

Something we neither give nor do to students, it is the process of nourishing or rearing towards a competent professional; development of power and formation of character of the learners.

Supervision on the other hand was defined by Onions (1973) as "directing or inspecting; exercising control." This difference in the definition means that student learning in the clinical setting has developed from training of skills to facilitation of the development of a student into a professional physiotherapist. Higgs (1992) described the primary role of clinical educators as that of providing competent clinical role models, facilitating and managing students' learning and empowering students to learn and to take control of, and responsibility for, their learning.

The role that the clinical educators must take is not without constraints and concerns. In 1988 Best described constraints that clinical educators have in their involvement with students as: 
- Physiotherapists' primary ethical responsibility for patient treatment.

- Physiotherapists' motivation in accepting the role of clinical educator.

- Inadequate preparation by informal training for the task of clinical education.

- The fact that clinical education is regarded as a time consuming and non-reimbursable input of time for the physiotherapist.

- The fact that few clinical educators have the luxury of reduced case loads in order to allocate more time to student activities, and therefore see time as a constraint to clinical education.

Concerns of clinical educators regarding their involvement with student training were identified in a one-day workshop organized by the Medical University of Southern Africa for clinical educators and lecturers:

- Clinical educators are confused about expectations regarding their evaluation of the students' clinical performance.

- Clinical educators would like guidance with evaluation of clinical performance.

- Emphasis on certain aspects of clinical practice differs between lecturers and clinical educators.

- Students are not well prepared for the clinical blocks.

- Students lack self-confidence, assertiveness and initiative.

- Most students lack responsibility towards their patients.

In a more extensive study of 39 clinical educators other concerns were raised (Mbambo, 1998). Some of the clinical educators raised concerns about the evaluation format used by the various universities. They felt that the evaluation tool was not objective and did not really evaluate the clinical competence of the students. Other clinical educators felt that communication regarding the curricula was not effective. They suggested that the universities should include clinical educators in the development of curricula and the revision thereof.

\section{PREPARATION OF CLINICAL EDUCATORS}

Since the early days of the profession, physiotherapy clinicians have been involved in the clinical education of physiotherapy students. However, although health care professions value clinical education, little attention has been given to preparing therapists for their teaching role (Christ-Hickerson, 1986). It appears that the problem of preparation of clinical educators is not unique to physiotherapy as other health professions have similar problems. In a study by Christie et al (1985) among occupational therapy clinical educators, it was found that the majority of the clinical educators were dissatisfied with the preparation they received for their clinical teaching role. Many of them indicated that different aspects of training were required for adequate preparation for the clinical education role. The objectives of the training should be:

- To improve supervisory skills by developing competency in assessing the needs of the students, establishing performance objectives and expectations, evaluating student performance, structuring the students' clinical experience and adapting their clinical teaching approach to meet specific students' needs that have been identified.

- To improve teaching skills by providing theoretical knowledge of the teaching-learning process and assistance in improving clinical teaching techniques.

- To enable clinical educators to handle students' clinical and personal problems that hinder their effective learning by providing information regarding curriculum changes and how to counsel students.

The sentiments expressed by these clinical educators indicate that they have insight into their training and therefore preparatory needs.

The study of student health visitors and teachers conducted by Fish et al (1989) revealed evidence that many clinical educators were not aware of the skills and strategies required in clinical education and they did not acknowledge the complexities of enabling students to learn from experience. This situation was seen to be aggravated by the fact that some of the clinicians who were required to offer clinical education to students did not have sufficient clinical experience themselves. The findings by Fish et al (1984) are supported by an earlier study by Orton (1981) which was done on clinical education in nursing. This study suggested that the models and skills of clinical education were not fully recognized or understood by many qualified staff undertaking clinical education, even though many nursing sisters had attended a course in teaching and assessing of students. This indicates perhaps either a lack of a conceptual framework for clinical education in the educators' courses or that the courses alone are not adequate.

\section{THE SOUTH AFRICAN SCENARIO}

The clinical facilities used for physiotherapy students' clinical experience have changed in South Africa. The shift towards Primary Health Care and the lack of sufficient financial and therefore human resources in the tertiary health institutions have brought about this change. The clinical facilities used therefore are no longer in the vicinity of the academic institutions; some are more than five hundred kilometers away. It is important therefore to empower the clinical educators to deal with all aspects of clinical education because some of them do not have the luxury of nearby academic staff for consultation.

At the moment the following are the different systems used by the universities to either prepare or support their clinical educators:

- An 'outline' on clinical education is given to clinical educators to give them guidelines on what is required from the students in each clinical setting and how to allocate marks.

- Clinical educators are given a 20-hour course and workshops to prepare them for their role and they attend regular meetings where any problems they may encounter, are discussed.

- Clinical educators i.e. clinicians and lecturers meet at the beginning of the year to discuss objectives for clinical education and to revise the assessment form and procedural format for assessment of students' clinical performance. 
- Meetings are held once every term to discuss progress, problems and additional specific guidance structures for those who have specific problems.

- Clinical educators are given objectives and evaluation forms for specific clinical settings.

A few of the universities create the opportunity for the lecturers and clinical educators to discuss clinical education objectives and the problems encountered during clinical education. There seems to be a lack of empathy though between the lecturers and the clinical educators in relation to their needs and expectations of each other. Central to this concern or lack of empathy is its impact on learning outcomes and the overall quality of clinical education.

\section{NEEDS OF THE CLINICAL EDUCATORS - SOUTH AFRICAN CONTEXT}

Physiotherapists have varying perceptions of the task of clinical educators, which are influenced by their own experiences, work situations and recent student contact, professional development and interpersonal needs. With the physiotherapy training transformed from "drilling" students to education and learning, active teaching takes place in a widening variety of clinical areas. The giving and receiving of feedback and encouraging initiatives are also now the way to groom professionals of the future. This means that the role of the clinical educators and expectations are changing and hence their needs.

The present systems used by the universities therefore may not be sufficient to achieve the objective they are meant for. In a study done by Mbambo in 1998 to establish the needs of clinical educators, the clinical educators identified the following.

\section{Aspects of planning that clinical edu- cators need to be involved in:}

\section{- Time-table and student placement}

The clinical educators perceive planning of timetables and placing students in the clinical settings as part of active involvement. Their involvement in planning timetables will ensure that the clinical educational programme can more or less fit in with the daily routine of the clinical setting with minimum disruption. Their participation will also give them the opportunity to plan the learning experiences of students in accordance with the university regulations, the types of patients available, duration of treatment and hospitalization.

\section{- Clinical objectives and pre-clinical preparation of students}

Discussion of clinical objectives and pre-clinical preparation of students were the areas which the clinical educators felt would minimize if not eradicate, the dichotomy between the lecturing staff and the clinical supervisor. This dichotomy tends to confuse students and may cause anxiety when they have to treat patients.

\section{Needs of the supervisors regarding training courses for themselves}

Most of the clinical educators feel that there is a need for preparation for the role of being a clinical educator. Some of the clinical educators who share this sentiment have been trained for their role and therefore had experienced the benefits of being trained for clinical education.

With regard to the areas of training that need to be included in a training course, most clinical educators indicated the following:

- Teaching methods

- Assessment of students

- Awarding of marks

- Interpersonal skills

- Setting of objectives

The foregoing findings indicate that the clinical educators have insight into their needs and that they acknowledge that they need to improve and broaden their educational skills. They therefore appreciate that their role has changed and has become more complex.

\section{RECOMMENDATIONS}

- Staff from university departments need to show appreciation for the work done by the clinical educators so that their morale and motivation can be boosted. This can be done using the following strategies:
- Paying an honorarium to the clinical department for the clinical education that they offer to students.

- The universities that train physiotherapists should give clinical educators a summative clinical examiner's status so that they can act as external examiners. Clinical educators should be invited as sessional lecturers in their areas of expertise.

- Clinical educators should pay reduced fees for continuing education courses run by the universities.

- Staff from university departments should offer academic support for the clinical educators

- Their training needs should be established and courses designed to meet these needs.

- They should be given access to university libraries or if the clinical settings are situated far from the libraries, they should get recent articles from journals to which the universities subscribe.

- They should be supported in their research endeavours and should be encouraged and assisted to present papers or posters at congresses

- Clinical educators should be included in clinical education planning so that they can be equal partners in professional education

- They should be invited to planning sessions of the clinical programmes.

- They should be involved in decision making on which clinical setting is to be utilized for which clinical block, and the number of students to be accommodated.

- They should get involved in setting of the clinical objectives and advise the universities on the activities and experiences available to achieve these objectives

In 1987 Barnett et al outlined prerequisites for equal partnership in clinical education: the academic staff must be conversant with realities and contextual variables of contemporary practice, even though they are not necessarily fully involved with them AND the clinical staff taking part in clinical education must also have a measure of awareness 
of the thinking underlying educational change, while not allowing undue concern for educational theory to impede their ability to deal with practical problems in the clinic.

a The roles of the clinical educating personnel, that is, lecturers and clinical educators, should be clearly defined. A supervision policy needs to be developed which will spell out all the different aspects of clinical education. This policy should include:

- The roles of the lecturers and clinical educators in clinical education and how education will be shared.

- How clinical education will be conducted, that is, activities to be executed.

- When, during the block, these activities are to be executed.

- When the students are to be evaluated during the block and by whom.

- What the expectations of all the stakeholders in clinical education are.

- The clinical educators should be made aware of the students' expectations so that they can ensure that their interaction with the students fulfills the students' expectations. In a study done by Kekana and Hlwathi (1998) among students from MEDUNSA and universities of Pretoria and W.itwatersrand four categories of expectations were identified by the students: (Table 1)

The same study recommended workshops between students and clinical educators where expectations and needs would be discussed. These workshops should be organized by the lecturers and funded by the universities.

\section{CONCLUSION}

The literature reviewed and the empirical investigation that was done reveal that the clinical educators have a need for support and guidance in clinical education. They need moral support; recognition of the role they play in clinical education, inclusion in planning and decision making on clinical education issues and preparation for their role as clinical educators. They perceive themselves to be competent in their role but realize the changes that have taken place in their role and know their educational

TABLE 1: CATEGORIES OF EXPECTATIONS ,

\begin{tabular}{|l|l|}
\hline CATEGORY & EXPECTATIONS \\
\hline Communication & Open discussion of issues with students \\
\hline & Prompt provision of feedback on clinical performance \\
\hline Supervision activities & $\begin{array}{l}\text { Allow answers to questions } \\
\text { independence }\end{array}$ \\
\hline & Accurate documentation of student evaluation progressive and appropriate \\
\hline & $\begin{array}{l}\text { Make the formal evaluation a constructive process } \\
\text { as they arise }\end{array}$ \\
\hline & $\begin{array}{l}\text { Make the relationship between academic knowledge } \\
\text { and clinical practice }\end{array}$ \\
\hline Professional skills & $\begin{array}{l}\text { Assist the students to define specific objectives for the } \\
\text { clinical education experience }\end{array}$ \\
\hline $\begin{array}{l}\text { Demonstrate professional behaviour as a member of } \\
\text { the health care teamDemonstrate basic theoretical } \\
\text { knowledge and teaching skills }\end{array}$ \\
\hline Interpersonal relations \\
$\begin{array}{l}\text { Establish an environment in which the students feel } \\
\text { comfortable }\end{array}$ \\
\begin{tabular}{l} 
Demonstrate positive regard for students as a person \\
\hline
\end{tabular} \\
\hline
\end{tabular}

needs to fulfill this changed role. Workshops therefore, with the lecturers and clinical educators, should be run to continually engage in discussions about the clinical educators' needs, the problems encountered during clinical education and other matters of mutual interest including sharing of ideas.

\section{REFERENCES}

Barnett RA, Becher RA and Cork NM 1987 Models of professional preparation: Pharmacy, nursing and teacher education. Studies in Higher Education, 12, (1),-51 - 63

Best D 1988 Physiotherapy Clinical Supervision: Effectiveness and Use of Models. The Australian Journal of Physiotherapy, 34, (4), $209-214$

Christ Hickerson PA, 1986 Contemporary issues in clinical education. 1, (3), Slack Incorporated, New Jersey.

Christie BA, Joyce PC and Moeller PL 1985 Fieldwork experience, Part II: The supervisors' dilemma. American Journal of Occupational Therapy, 39, (10), 675-681

Coates M 199 I Clinical education: Students and clinical tutors' views. Physiotherapy, 77, (5), 351-354
Cross V 1994 From Clinical Supervisor to Clinical Educator: Too much to ask? Physiotherapy, 80, (9), $609-611$

Daloz LA 1986 Effective teaching and mentoring. Jossey-Bass, London.

Fish D, twin S and Purr B 1989 How to enable learning through clinical practice. Pilot study report No. 1. West London Institute of Higher Education, London

Higgs J1992 Managing Clinical Education. Physiotherapy, 78, (11), $822-827$

Kekana EM and Hlwathi TM 1998 Competent clinical supervisor: Physiotherapy students' perspective. Unpublished undergraduate research project

Mbambo NP 1998 The needs in physiotherapy clinical education: Clinical educators' perspective. Unpublished postgraduate research project.

Onions CT (ed) 1973 Shorter Oxford English Dictionary. On Historical Principles, Oxford University Press

Orton HD 1994 Ward learning climate. Royal College of nursing, London

Wastaff P 1988 The great debate. Proceedings of Association of teachers of CSP, Spring Conference, $16-18$ 